\title{
Giant Condylomata Acuminata or Buschke-Löwenstein Tumour: Clinic and Dermoscopy
}

\author{
Dahhouki Sara $^{1 *}$, Achehboune Kaoutar ${ }^{1}$, Bennani Mounia ${ }^{1}$, Douhi Zakia ${ }^{1}$, Elloudi Sara ${ }^{1}$, Baybay Hanane ${ }^{1}$, \\ Mernissi Fatima Zahra', Mohammed Amine Houssa ${ }^{2}$, Cherkaoui Belmaati Ghita ${ }^{2}$ and Aya Oufkir ${ }^{2}$ \\ ${ }^{I}$ Department of Dermatology, Hassan II Hospital University Sidi Harazzem Fez, Morocco \\ ${ }^{2}$ Department of Plastic and Reconstructive surgery, Hassan II Hospital University, Fez, Morocco
}

Correspondence should be addressed to Dahhouki Sara, dahhoukisara@gmail.com

Received: June 01, 2020; Accepted: June 10, 2020; Published: June 17, 2020

\section{INTRODUCTION}

The Buschke-Löwenstein tumor, also known as, giant condyloma acuminatum is an extremely rare sexually transmitted disease associated due to human papilloma virus infection, mostly Type 6 or 11 . It affects the anogenital region. It is not just locally aggressive and destructive, but also, malignant transformation is possible. We report a case of a 48-year-old male patient with a perianal Buschke-Löwenstein tumour [1,2].

\section{CLINICAL IMAGE}

This is a 48-year-old man, who has unprotected sexual intercourse with multiple partners; presented with a progressively enlarging mass in the pubis region since 8 years. At our clinical examination: we objected mass located in perinea, which was bulky, friable, exophytic and cauliflower like. Dermatoscopic findings include multiple filiform and round projections, with dendritic blood vessels (Figure 1 - Figure 3). No inguinal lymphadenopathy was noted. The examination of the anal and oral mucosa was normal. Systemic examination was normal. Laboratory examination showed that haematological and biochemical investigations were within normal limit. HIV test was negative. The diagnosis retained was giant condyloma acuminatum. Radical local excision of the lesion was performed and histopathological examination demonstrated hyperkaratosis, papillomatosis, and acanthosis with presence of koilocytosis of the epithelium, intact basement membrane without malignant transformation or invasiveness. Three months after surgery, there has been no local or remote recurrence.

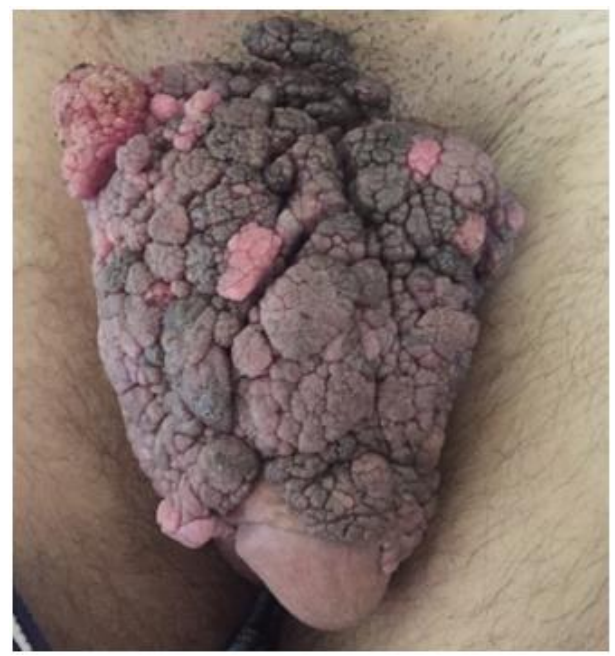

Figure 1: Bulky, friable, exophytic and cauliflower like mass in perinea.

Citation: Dahhouki Sara, Giant Condylomata Acuminata or Buschke-Löwenstein Tumour: Clinic and Dermoscopy. J Clin Cases Rep 3(S2): 7-8.

2582-0435/@ 2020 The Authors. Published by TRIDHA Scholars. 


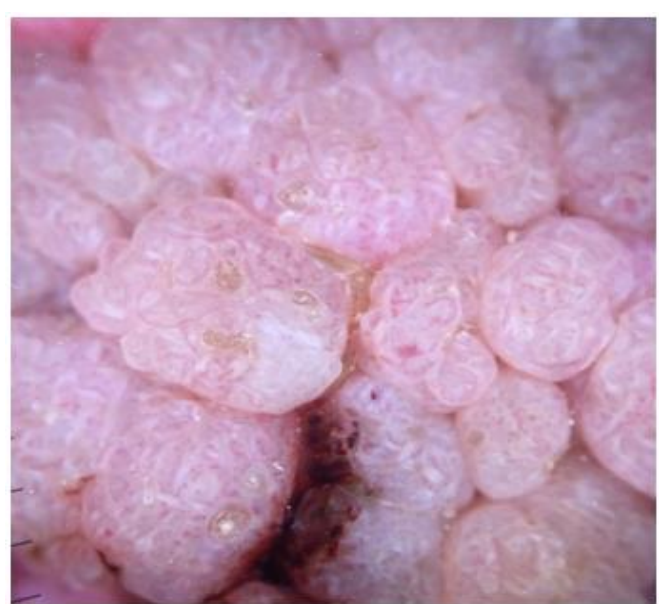

Figure 2: Dermoscopic features multiple filiform and round projections, with dendritic blood vessels.

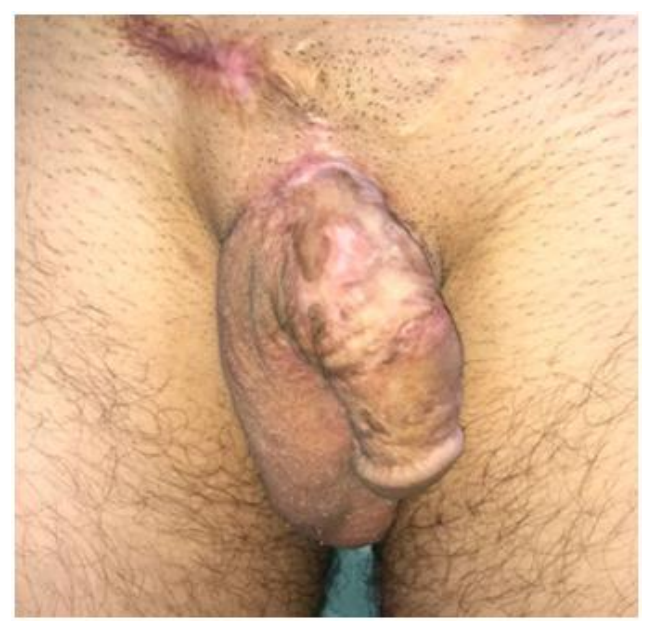

Figure 3: Control after tumor excision.

\section{REFERENCES}

1. Chu GY, Chang TCC, Chang CH (2013) Buschke-Löwenstein tumor (giant condyloma acuminatum) successfully treated by topical photodynamic therapy: A case report. Dermatologica Sinica 31(2): 94-97.

2. Gholam P, Enk A, Hartschuh W (2009) Successful surgical management of giant condyloma acuminatum (BuschkeLöwenstein tumor) in the genitoanal region: A case report and evaluation of current therapies. Dermatology 218(1): 5659. 